\title{
How does per-oral endoscopic myotomy compare to Heller myotomy? The Latin American perspective
}

\section{(ㄷ)(1)}

Authors

Michel Kahaleh ${ }^{1}$, Amy Tyberg ${ }^{1}$, Supriya Suresh ${ }^{2}$, Arnon Lambroza ${ }^{2}$, Monica Gaidhane ${ }^{1}$, Felipe Zamarripa ${ }^{3}$, Guadalupe Ma Martínez ${ }^{3}$, Juan C. Carames ${ }^{4}$, Eduardo T. Moura ${ }^{5}$, Galileu F. Farias ${ }^{5}$, Maria G. Porfilio ${ }^{6}$, Jose Nieto ${ }^{7}$, Mario Rey ${ }^{8}$, Fernando Rodriguez Casas ${ }^{8}$, Oscar V. Mondragón Hernández ${ }^{9}$, Romulo Vargas-Rubio ${ }^{10}$, Raul Canadas ${ }^{10}$, Albis Hani ${ }^{10}$, Guillermo Munoz ${ }^{1}$, Bismarck Castillo ${ }^{11}$, Hannah P. Lukashok ${ }^{12}$, Carlos Robles-Medranda ${ }^{12}$, Eduardo G de Moura ${ }^{5}$

Institutions

1 Rutgers Robert Wood Johnson Medical School, New Brunswick, New Jersey, United States

2 Weill Cornell Medical School, New York, New York, United States

3 Hospital Juarez de Mexico, Mexico City, Mexico

4 Santander Hospital, Reynosa, Mexico

5 Hospital das Clinicas, Sao Paulo, Brazil

6 Hospital Escuela Dr.Ramon Madariaga, Posadas, Argentina

7 Borland-Groover, Jacksonville, Florida, United States

8 La Policia Hospital, Bogota, Colombia

9 Mexican Institute of Social Security, Mexico City, Mexico

10 San Ignacio University Hospital, Bogota, Colombia

11 Gastromedica Clinic, Managua, Nicaragua

12 Ecuadorian Institute of Digestive Diseases, Guayaquil, Ecuador

submitted 18.11.2019

accepted after revision 12.6.2020

\section{Bibliography}

Endoscopy International Open 2020; 08: E1392-E1397

DOI 10.1055/a-1223-1521

ISSN 2364-3722

(c) 2020. The Author(s).

This is an open access article published by Thieme under the terms of the Creative Commons Attribution-NonDerivative-NonCommercial License, permitting copying and reproduction so long as the original work is given appropriate credit. Contents may not be used for commecial purposes, or adapted, remixed, transformed or built upon. (https://creativecommons.org/licenses/by-nc-nd/4.0/)

\section{Corresponding author}

Michel Kahaleh, MD, AGAF, FACG, FASGE, Professor of Medicine, Clinical Director of Gastroenterology, Chief of Endoscopy, Robert Wood Johnson University Hospital, New Brunswick, NJ 08901, United States

Fax: +1-732-235-5537

mkahaleh@gmail.com

\section{ABSTRACT}

Background and study aims Both Heller myotomy (HM) and per-oral endoscopic myotomy (POEM) are efficacious therapies for achalasia. The efficacy and safety of POEM vs $\mathrm{HM}$ in Latin America and specifically in patients with Chagas disease is unknown.

Patients and methods Consecutive patients undergoing either HM or POEM for achalasia were included from nine Latin American centers in a prospective registry over 5 years. Technical success was defined as undergoing a successful myotomy. Clinical success was defined as achieving an Eckardt score <3. Data on demographics, procedure info, Eckardt score, and adverse events (AEs) were collected. Student's $t$ test, Chi squared, and logistic regression analyses were conducted.

Results One hundred thirty-three patients were included (59 male; 44\%; mean age 47). POEM was performed in 69 patients, HM in 64 patients. A total of 35 patients had Chagas disease, 17 of 69 in the POEM group, 18 of 64 in the HM group. Both groups had significant reduction in Eckardt scores $(P<0.00001)$, but successful initial therapy was significantly higher in the POEM group compared to the HM group $(P=0.01304)$. AEs were similar in both group $(17 \%$ vs $14 \%$ ) and consisted of pneumothorax ( $n=3$ vs 2 ), bleeding requiring transfusion ( $n=3$ vs 2 ), and mediastinitis $(n=3$ vs 1 ). Hospital stay was longer in the HM group than in the POEM group $(P<0.00001)$. In the Chagas subgroup, postprocedure Eckardt score in the POEM group was significantly reduced by 5.71 points $(P<0.00001)$ versus 1.56 points in the HM group ( $P=0.042793)$.

Conclusion Both HM and POEM are efficacious for achalasia, but POEM was associated with higher initial therapy success and shorter hospital stay in Latin America. In Chagas patients with achalasia, POEM was significantly more effective than HM. 


\section{Introduction}

Both Heller myotomy (HM) and per-oral endoscopic myotomy (POEM) are efficacious therapies for patients with achalasia. In Latin America, achalasia is frequently caused by Chagas disease. Chagas disease currently affects 6 to 7 million people in Mexico, Central and South America, and is currently spreading throughout the world. Even though Trypanosoma cruzi is endemic in rural areas of Central and South America, global migration, especially from rural areas, has aided Chagas disease to present in areas unthinkable until recent years. Roure et al. showed data from 62 patients in non-endemic European areas presenting esophageal Chagas affection [1,2]. As of 2013, approximately 36.7 million people migrated out of Latin America and the Caribbean and were residing elsewhere in the world, predominantly in North America [3], bringing Chagas disease to urban environments [4]. Moreover, there have been reported cases of positive Trypanosoma infection in Italy [5] and Switzerland [6].

Patients with Chagas esophageal disease present with absence of esophageal sphincter opening, aperistalsis, and megaesophagus [7]. Alternatively, achalasia is a motility disorder, caused by lack of relaxation of the lower esophageal sphincter (LES). Despite presenting minor differences, both conditions share essentially an identical clinical presentation and response to treatment [8].

Treatment is focused on improving outflow to produce symptomatic relief [9-11] which can be accomplished by either HM or POEM.

Despite the rise of POEM in achalasia treatment, the efficacy and safety of POEM vs HM in Latin America and specifically in patients with Chagas disease is unknown. This study aims to evaluate the efficacy and safety of POEM vs HM in Latin America and in patients with Chagas disease.

\section{Patients and methods}

Consecutive patients from nine tertiary centers in Latin America undergoing either HM or POEM over 5 years were included in an institutional review board-approved registry (Clinicaltrials. gov Identifier: NCT02162589) and analyzed retrospectively. Patients were diagnosed with either idiopathic achalasia or Chagas disease. Achalasia was diagnosed by barium studies and esophageal manometry and Chagas disease was confirmed with serologic studies.

Data on demographics, age, gender, and duration of disease and prior treatment were captured. Patients with achalasia were classified according to type (I, II or III).

\section{Procedure technique}

POEM

All POEMs were done under general anesthesia and with carbon dioxide insufflation. An upper endoscope was inserted through the mouth and the esophagus was irrigated with gentamicin solution. A multipurpose knife (triangle tip knife, Flush Knife, Hybrid Knife or Hook knife) was used to create an esophageal mucosal incision, at $12 \mathrm{~cm}$ proximal to the gastroesophageal junction (GEJ). Anterior or posterior orientation was left at the discretion of the endoscopist. A mixture of Indigo Carmine or methylene blue and $0.9 \%$ saline solution was injected submucosally to make a bleb and to widen the submucosal space. The knife was then used to carefully dissect through deep submucosa to create a tunnel. The width of the submucosal tunnel was about half the circumference of the esophagus. Coagulation grasper forceps were used to coagulate any large or bleeding vessels and needle decompression was performed if $\mathrm{CO}_{2}$ retention was suspected. To confirm adequacy of length of the tunnel beyond the LES, the blue discoloration of the cardiac mucosa was visualized in the retroflexed view from inside the stomach. At about $2 \mathrm{~cm}$ from the mucosal entry, circular muscle dissection was performed to a length of at least $8 \mathrm{~cm}$ with the dissection extending at least $2 \mathrm{~cm}$ below the cardia. In the last $5 \mathrm{~cm}$, a full-thickness myotomy was performed. The submucosal tunnel was then irrigated with gentamicin solution and the mucosal entry site was closed with hemostatic clips.

\section{Heller myotomy}

HM procedures were performed using laparoscopy via a transabdominal approach. The diaphragmatic hiatus was dissected open to allow for mobilization of the medial esophagus to at least $6 \mathrm{~cm}$ proximal to the esophagogastric junction (EGJ). A myotomy of both the circular and longitudinal muscle layers was performed proximal to the EGJ to $2 \mathrm{~cm}$ into the proximal stomach. The crura was then loosely approximated posteriorly, allowing for easy passage of a 5-mm instrument through the hiatus. A $270^{\circ}$ posterior (Toupet) fundoplication or anterior $180^{\circ}$ (Dor) fundoplication for postoperative reflux control was then performed.

All patients received intravenous (IV) broad-spectrum antibiotics and were kept nothing by mouth until a swallow study was done the following day to ensure no contrast extravasation. If no leak was observed, then a patient was started on clear liquid diet.

\section{Definition}

Technical success was defined as successful myotomy. The primary outcome was clinical success defined as Eckardt score $\leq 3$. Secondary outcomes included adverse events post-procedure and difference in LES pressure pre- and post- POEM on manometry.

A graphical representation of the study design is shown -Fig. 1.

\section{Follow-up}

High-resolution manometry (HRM) was used in all cases before and after POEM.

Esophagograms pre- and post-POEM were compared in terms of decreased distal obstruction and improved transit time.

Eckart score, HRM, and esophageal transit were evaluated at 3,9 , and 12 months post-POEM. 


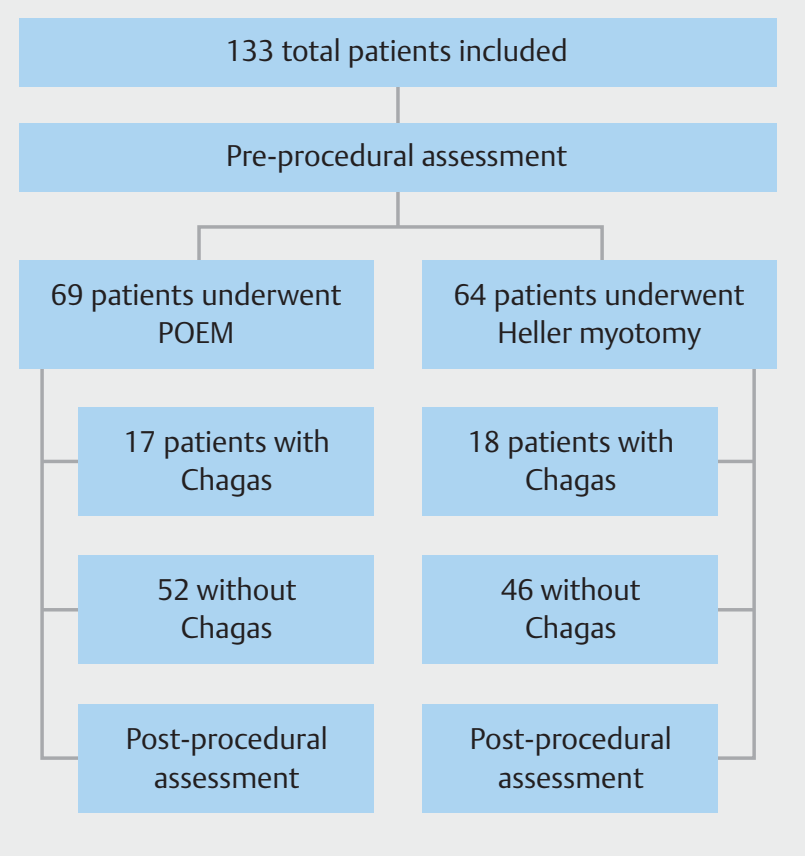

- Fig. 1 Study design.

\section{Statistical analysis}

Statistical analyses were conducted using SPSS 15.0 statistics software (SPSS Inc, Chicago, Illinois, United States). Chi Squared and Fisher's exact tests were used for comparing categorical variables in the two groups and Student's $t$ test was conducted for comparing continuous variables

Logistic regression was conducted to determine the odds ratio for clinical success in Chagas patients. Two-sided $P<.05$ was considered statistically significant.

All authors had access to the study data and have reviewed and approved the final manuscript.

\section{Results}

A total of 113 patients were included, 59 of whom were male (44\%), mean age 47; 69 patients underwent POEM (29 M [42\%], mean age 47.3) and 64 underwent HM (30 M [47\%]; mean age 45.6). Forty-one patients had received previous treatment: pneumatic dilations $n=35$, Botox injection $n=6$. Pre-procedural Eckardt score was 8.72 (STD 1.7) for the POEM group, and 7.4 (STD1.3) for the HM group. A total of 35 patients had Chagas disease, 17 of 69 in the POEM group, 18 of 64 in the HM group. Demographics and clinical characteristics of $\mathrm{HM}$ and POEM groups are shown in $>$ Table 1 and $>$ Table 2 .

The technical success rate was $100 \%$ in both groups.

Patients in both groups had a significant reduction in Eckardt score by 6.88 points in POEM group $(P<0.00001)$, and by 3.77 points in the HM group $(P<0.00001)$. Clinical success during initial therapy was significantly higher in the POEM group (59/69, 86\%) compared to the HM group (39/64, 60\%) (difference $P=0.001304)$.
- Table 1 POEM vs HM demographics and clinical characteristics.

\begin{tabular}{|c|c|c|c|}
\hline Characteristic & POEM $(\mathrm{N}=69)$ & Heller $(\mathrm{N}=64)$ & $P$ Value \\
\hline Age (mean) & $\begin{array}{l}47.3 \mathrm{yr} \\
\text { (15.9 STD) }\end{array}$ & $\begin{array}{l}45.6 \mathrm{yr} \\
\text { (STD 10.5) }\end{array}$ & NS \\
\hline Gender - male & $29(42 \%)$ & $30(47 \%)$ & \\
\hline $\begin{array}{l}\text { Duration of } \\
\text { disease }\end{array}$ & $4.9 \mathrm{yrs}$. & 10.2 yrs. & $<.00001$ \\
\hline Achalasia & & & NS \\
\hline Type I & $25(36 \%)$ & $24(38 \%)$ & \\
\hline Type II & 34 (49\%) & $31(48 \%)$ & \\
\hline Type III & $10(15 \%)$ & $9(13 \%)$ & \\
\hline Chagas & $17(25 \%)$ & $18(28 \%)$ & NS \\
\hline Non-Chagas & $52(75 \%)$ & $46(72 \%)$ & \\
\hline Prior therapy & $\begin{array}{l}13 \text { dilation, } 6 \\
\text { Botox }\end{array}$ & 22 dilation & NS \\
\hline
\end{tabular}

- Table 2 POEM vs HM Clinical Results

\begin{tabular}{|c|c|c|c|}
\hline & $\begin{array}{l}\text { POEM Group } \\
(\mathrm{N}=69)\end{array}$ & $\begin{array}{l}\text { HM Group } \\
(N=64)\end{array}$ & $P$ Value \\
\hline $\begin{array}{l}\text { Pre-procedure } \\
\text { Eckardt score }\end{array}$ & 8.72 (STD 1.7) & 7.4 (STD 1.3) & $<.00001$ \\
\hline $\begin{array}{l}\text { Post-procedure } \\
\text { Eckardt score }\end{array}$ & 1.84 (STD 1.9) & 3.6 (STD 2.4) & $<.00001$ \\
\hline Adverse events & $12(17 \%)$ & $9(14 \%)$ & \multirow[t]{5}{*}{ NS } \\
\hline Mucosal defect & 7 & - & \\
\hline Pneumothorax & 2 & 3 & \\
\hline Bleeding & 2 & 3 & \\
\hline Mediastinitis & 1 & 3 & \\
\hline $\begin{array}{l}\text { Initial therapy } \\
\text { success }\end{array}$ & $59(86 \%)$ & $39(60 \%)$ & 0.001304 \\
\hline Repeat therapy & $10(14 \%)$ & $23(40 \%)$ & $<.00001$ \\
\hline Heller & 2 & 0 & \\
\hline POEM & 8 & 23 & \\
\hline Total hospital days & 1.1 & 1.6 & $<.00001$ \\
\hline $\begin{array}{l}\text { Total follow-up } \\
\text { duration }\end{array}$ & $16.8 \mathrm{mo}$ & $22.9 \mathrm{mo}$ & 0.000151 \\
\hline $\begin{array}{l}\text { Pre-procedure } \\
\text { LES pressure }\end{array}$ & $\begin{array}{l}38.66 \mathrm{mmHg} \\
\text { (STD 26.9) }\end{array}$ & $\begin{array}{l}38.8 \mathrm{mmHg} \\
(\mathrm{STD} 8.4)\end{array}$ & NS \\
\hline $\begin{array}{l}\text { Post procedure } \\
\text { LES pressure }\end{array}$ & $\begin{array}{l}14.3 \mathrm{mmHg} \\
(\text { STD 6.3) } \\
24.8 \mathrm{mmHg}\end{array}$ & $\begin{array}{l}19.8 \mathrm{mmHg} \\
(\text { STD 12.2) }\end{array}$ & .00231 \\
\hline
\end{tabular}

POEM, per-oral endoscopy myotomy; HM, Heller myotomy; LES, lower esophageal sphincter. 
In the POEM group, post-procedure LES pressure was reduced by $24.78 \mathrm{mmHg}$ points $(P \leq 0.00001)$, while in the Heller myotomy group, it was reduced by $19.05 \mathrm{mmHg}(P \leq$ $0.00001)$. The reduction in post-procedure LES pressure was higher in the POEM group compared to the Heller myotomy group $(14.3 \mathrm{mmHg}$ vs $19.2 \mathrm{mmHg}, P=0.00231)$ even though the pre-procedure LES pressure average was similar for both groups ( $P=0.943369)$.

Rates of AEs were similar in both groups and consisted of pneumothorax (POEM $n=3$ vs $H M n=2$ ), bleeding requiring transfusion (POEM $n=3$ vs $H M n=2$ ), and mediastinitis (POEM $n=3$ vs $\mathrm{HM} n=1$ ). Two pneumothoraxes (one in each group) required thoracentesis. All cases of mediastinitis were managed conservatively with IV antibiotics. Mucosal defects requiring clips were documented in seven POEM patients. All patients were discharged home fully recovered. Hospital stay was longer in the HM group than in the POEM group $(P<0.00001)$.

In the Chagas subgroup, post-procedure Eckardt score in the POEM group was significantly reduced by 5.71 points $(P<$ 0.00001 ) and 12 patients (71\%) reached achieved success; post-procedure Eckardt score was reduced by 1.56 points in the HM group $(P=0.042793)$ but only four patients $(22 \%)$ achieved clinical success. Multivariable analysis did not identify factors associated with clinical failure or predictive of clinical success. In the Chagas group, post-procedure Eckardt score was reduced by 3.57 points ( $P \leq 0.00001)$, while in the non-Chagas group, it was reduced by 6.03 points $(P \leq 0.00001)$. In the Chagas group, post-procedure LES pressure was reduced by $12.74 \mathrm{mmHg}$ points $(P \leq 0.00001)$, while in the non-Chagas group, it was reduced by $25.11 \mathrm{mmHg}(P \leq 0.00001)$. Repeat intervention was much higher in the Chagas group compared to the non-Chagas group [18 (51\%) vs 17 (17\%), $P=.000085$ ].

The mean POEM procedure time in the Chagas group was 120 minutes (STD 11.7 minutes) vs 94 minutes (STD 7.2 minutes) in the non-Chagas group.

A comparison of clinical characteristics in the Chagas vs nonChagas group is shown in $>$ Table 3 . Twenty patients had postoperative reflux: 12 in the POEM group and eight in the HM group. The difference was not statistically significant.

\section{Discussion}

Historically, HM has been the gold standard treatment for achalasia [12-18]. HM improves symptoms in $89 \%$ of patients, and combined with fundoplication, is a very safe operation with a mortality rate of $0.1 \%$ [19]. Since 2008 , POEM has proven its efficacy in the treatment of achalasia and it is now considered an alternative first-line therapy by many. POEM can be offered for different esophageal diseases [20-25], is cost-saving [26], and provides a longer myotomy [21], with similar long-term benefits as compared to HM [27, 28], while reducing post-procedural pain [29]. In addition, endoscopic myotomy has proven to be a promising technique folr other esophageal conditions, such as Jackhammer esophagus [30] and as a "salvation technique" for patients with recurrent symptoms after HM [31-33]. The population in Latin America is unique in that a large proportion of patients with achalasia have Chagas disease as the etiology.
- Table 3 Clinical characteristics in Chagas vs non-Chagas groups.

\begin{tabular}{|c|c|c|c|}
\hline Characteristic & $\begin{array}{l}\text { Chagas } \\
(N=35)\end{array}$ & $\begin{array}{l}\text { Non-Chagas } \\
(\mathrm{N}=98)\end{array}$ & $P$ Value \\
\hline Duration of disease & $7.8 \mathrm{yr}$ & $7 \mathrm{yr}$ & NS \\
\hline Achalasia & & & NS \\
\hline Type I & $15(43 \%)$ & $39(40 \%)$ & \\
\hline Type II & $20(57 \%)$ & $56(57 \%)$ & \\
\hline Type III & 0 & $3(3 \%)$ & \\
\hline $\begin{array}{l}\text { Pre-procedure } \\
\text { Eckardt score }\end{array}$ & 8 (STD 1.6) & 8.1 (STD 1.7) & NS \\
\hline $\begin{array}{l}\text { Post-procedure } \\
\text { Eckardt score }\end{array}$ & $\begin{array}{l}4.22 \\
(\text { STD 2.66) }\end{array}$ & $\begin{array}{l}2.1 \\
(\text { STD 1.9) }\end{array}$ & $<.00001$ \\
\hline $\begin{array}{l}\text { Pre-procedure } \\
\text { LES pressure }\end{array}$ & $\begin{array}{l}36.26 \\
(\text { STD 12.1) }\end{array}$ & $\begin{array}{l}39.7 \\
(\text { STD 21.2) }\end{array}$ & NS \\
\hline $\begin{array}{l}\text { Post-procedure } \\
\text { LES pressure }\end{array}$ & $\begin{array}{l}23.7 \\
(\text { STD 13.1) }\end{array}$ & $14.8(7.5)$ & $<.00001$ \\
\hline Repeat Therapy & $18(51 \%)$ & $17(17 \%)$ & .000085 \\
\hline Heller & 1 & 3 & \\
\hline POEM & 17 & 14 & \\
\hline Total hospital days & 1.46 & 1.34 & NS \\
\hline $\begin{array}{l}\text { Total follow-up } \\
\text { duration }\end{array}$ & $20.7 \mathrm{mo}$ & $19.4 \mathrm{mo}$ & NS \\
\hline \multicolumn{4}{|c|}{$\begin{array}{l}\text { LES, lower esophageal sphincter; POEM, per-oral endoscopic myotomy; NS, } \\
\text { non-significant }\end{array}$} \\
\hline
\end{tabular}

Although the conditions are clinically similar, response to therapy may differ due to differences in disease. In this study, we compared response to therapy with $\mathrm{HM}$ versus POEM in patients in Latin America with achalasia, and specifically how Chagas disease responds.

In our study, we found high efficacy for both procedures in Latin America patients with achalasia, which is consistent with prior studies. However, there was significantly better clinical success with POEM compared to HM, a trend that persisted even when controlling for Chagas disease. This might be related to the long-standing disease, especially in the surgical group compared to the POEM group; indeed, patients in Latin America tend to wait longer to receive surgical treatment compared to an endoscopic approach. However, the overall Eckhardt score washigherinthePOEM group, consistent with a more symptomatic population and subsequently an even wider efficacy gap. Keeping in mind the non-randomized design, it still suggests that firstline therapy with POEM may be more effective in this population than HM. Priorstudies have demonstrated similar results in specificpopulations. Ameta-analysisbyZhangetalanalyzed fourstudies comparing POEM and $\mathrm{HM}$ and found that patients in the POEM group had lower Eckardt scores after POEM compared with the HM group [23]. Similarly, Schlottmann et al conducted a metaanalysis of HM versus POEM for achalasia, confirming that overall, POEM is more effective than the Heller procedure based on shortterm results [24]. 
Our subgroup analysis of patients exclusively with achalasia related to Chagas disease found better outcomes in the POEM group than in the HM group. Chagas patients had significantly higher clinical success rates, but also a larger decrease in Eckhardt score.

This is probably related to the diffuse scarring of the esophagus induced by Chagas disease and the ability to perform a longer myotomy when offering POEM. Though a randomized controlled trial is needed to properly demonstrate efficacy of endoscopic myotomy in treatment of Chagasic megaesophagus, our analysis, which included patients from different parts of the American continent, gives us incentives to widen use of POEM in scenarios other than idiopathic achalasia.

The $\mathrm{AE}$ rate in our study was $17 \%$, which is higher than seen in other studies $[16,23]$. This is likely related to the difficulty of performing POEM in Chagas disease due to scarring and adhesion of the mucosa to the muscularis. In addition, nearly onethird of patients in the study had undergone prior therapy for achalasia, which increases scarring and procedural complexity.

\section{Conclusion}

In conclusion, both HM and POEM are efficacious for achalasia, but POEM was associated with higher rates of success with initial therapy and shorter hospital stays in Latin America. In patients with Chagas with achalasia, POEM was significantly more effective than HM.

\section{Acknowledgements}

This paper was presented during Digestive Diseases Week 2018 as an oral presentation.

\section{Competing interests}

The authors have received research support from Boston Scientific, Interscope, Conmed, Pinnacle, Gore, Merit, and Olympus.

\section{References}

[1] World Health Organization. Chagas Disease Key Facts. http://www. who.int/news-room/fact-sheets/detail/chagas-disease-(americantrypanosomiasis)

[2] Roure $S$, Valerio L, Vallès $X$ et al. Oesophageal motility disorders in infected immigrants with Chagas disease in a non-endemic European area. United European Gastroenterol J 2016; 4: 614-620

[3] Conners EE, Vinetz JM, Weeks JR et al. A global systematic review of Chagas disease prevalence among migrants. Acta Trop 2016; 156: $68-78$

[4] Centers for Disease Control and Prevention. Travelers' Health. Chagas Disease (American Trypanosomiasis) https://wwwnc.cdc.gov/travel/ diseases/chagas-disease-american-trypanosomiasis

[5] Bargiggia G, Ruggeri M, Ortalli G et al. Congenital Chagas disease in a Bolivian newborn in Bergamo (Italy). Infez Med 2018; 26: 93-96
[6] Jackson Y, de Mello Pula DV, Finckh A et al. Chagas disease and systemic autoimmune diseases among Bolivian patients in Switzerland. Mem Inst Oswaldo Cruz 2018; 113: e170383

[7] Dos Santos CM, de Cassiani AR, do Nascimento WV et al. Timing of pharyngeal swallow events in Chagas' disease. Gastroenterol Res 2014; 7: 93-97

[8] Vicentine FPP, Herbella FAM, Allaix ME et al. Comparison of idiopathic achalasia and Chagas' disease esophagopathy at the light of high-resolution manometry. Dis Esophagus 2014; 27: 128-133

[9] Goldstein AM, Thapar N, Karunaratne TB et al. Clinical aspects of neurointestinal disease: Pathophysiology, diagnosis, and treatment. Dev Biol 2016; 417: 217-228

[10] Sánchez-Montalvá A, Moris M, Mego M et al. High Resolution esophageal manometry in patients with chagas disease: a cross-sectional evaluation. PLoS Negl Trop Dis 2016; 10: e0004416

[11] Arora Z, Thota PN, Sanaka MR. Achalasia: current therapeutic options. Ther Adv Chronic Dis 2017; 8: 101-108

[12] Pantanali CAR, Herbella FAM, Henry MA et al. Laparoscopic Heller myotomy and fundoplication in patients with Chagas' disease achalasia and massively dilated esophagus. Am Surg 2013; 79: 72-75

[13] Schlottmann F, Allaix ME, Patti MG. Laparoscopic Heller myotomy for achalasia technical aspects. Am Surg 2018; 84: 477-480

[14] Friscia ME, Buyske J. Laparoscopic Nissen Fundoplication and Heller myotomy. G Gloved Surg Introd to Common Proced 2009: 44-54

[15] Grimes KL, Inoue H. Per oral endoscopic myotomy for achalasia: a detailed description of the technique and review of the literature. Thorac Surg Clin 2016; 26: 147-162

[16] Inoue $\mathrm{H}$, Sato $\mathrm{H}$, Ikeda $\mathrm{H}$ et al. Per-Oral endoscopic myotomy: a series of 500 patients. J Am Coll Surg 2015; 221: 256-264

[17] Cho YK, Kim SH. Current status of peroral endoscopic myotomy. Clin Endosc 2018; 51: 13-18

[18] Torres-Villalobos G, Martin-Del-Campo LA. Surgical treatment for achalasia of the esophagus: laparoscopic heller myotomy. Gastroenterol Res Pract 2013; 2013: 708327

[19] Illés A, Farkas N, Hegyi P et al. Is Heller myotomy better than balloon dilation? A meta-analysis J Gastrointestin Liver Dis 2017; 26: 121-127

[20] Smith SP, Louie BE. The current state of per oral endoscopic myotomy for achalasia. J Vis Surg 2017; 3: 122

[21] Kumbhari V, Tieu AH, Onimaru M et al. Peroral endoscopic myotomy (POEM) vs laparoscopic Heller myotomy (LHM) for the treatment of Type III achalasia in 75 patients: a multicenter comparative study. Endosc Int Open 2015; 3: E195-E201

[22] Bhayani NH, Kurian AA, Dunst CM et al. A Comparative study on comprehensive, objective outcomes of laparoscopic Heller myotomy with per-oral endoscopic myotomy (POEM) for achalasia. Ann Surg 2014; 259: 1098-1103

[23] Zhang $\mathrm{Y}$, Wang $\mathrm{H}$, Chen $\mathrm{X}$ et al. Per-oral endoscopic myotomy versus laparoscopic Heller myotomy for achalasia: a meta-analysis of nonrandomized comparative studies. Medicine (Baltimore) 2016; 95 : e2736

[24] Schlottmann F, Luckett DJ, Fine J et al. Laparoscopic Heller myotomy versus peroral endoscopic myotomy (POEM) for achalasia. Ann Surg 2017; 267: 1

[25] Estremera-Arévalo F, Albéniz E, Rullán M et al. Efficacy of peroral endoscopic myotomy compared with other invasive treatment options for the different esophageal motor disorders. Rev Esp Enfermedades Dig 2017; 109: 578-586

[26] Khashab MA, Kumbhari V, Tieu AH et al. Peroral endoscopic myotomy achieves similar clinical response but incurs lesser charges compared to robotic heller myotomy. Saudi J Gastroenterol 2017; 23: 91-96 
[27] Ward MA, Gitelis M, Patel L et al. Outcomes in patients with over 1year follow-up after peroral endoscopic myotomy (POEM). Surg Endosc 2017; 31: 1550-1557

[28] Peng L, Tian S, Du C et al. Outcome of peroral endoscopic myotomy (POEM) for Treating achalasia compared with laparoscopic Heller myotomy (LHM). Surg Laparosc Endosc Percutan Tech 2017; 27: 6064

[29] Docimo S, Mathew A, Shope AJ et al. Reduced postoperative pain scores and narcotic use favor per-oral endoscopic myotomy over laparoscopic Heller myotomy. Surg Endosc 2017; 31: 795-800
[30] Dawod E, Saumoy M, Xu M-M et al. Peroral endoscopic myotomy (POEM) in jackhammer esophagus: a trick of the trade. Endoscopy 2017; 49: E254-E255

[31] Tyberg A, Sharaiha RZ, Familiari P et al. Peroral endoscopic myotomy as salvation technique post-Heller: International experience. Dig Endosc 2018; 30: 52-56

[32] Hungness ES, Sternbach JM, Teitelbaum EN et al. Per-oral endoscopic myotomy (POEM) after the learning curve. Ann Surg 2016; 264: 508 517

[33] Alves APR, de Oliveira PG, de Oliveira JM et al. Long-term results of the Modified Thal procedure in patients with chagasic megaesophagus. World J Surg 2014; 38: 1425-1430 